\title{
Os pensamentos sobre a verdadeira estimação das forças vivas e o surgimento de motivos críticos no pensamento de Kant
}

\author{
The thoughts on the true estimation of living forces and the \\ formation of critical motives in Kant's thought
}

\section{Diego Kosbiau Trevisan*}

Universidade de São Paulo (USP), São Paulo, SP, Brasil, Johannes Gutenberg-Universität Mainz (JGU), Mainz, Alemanha

\section{Resumo}

O objetivo do presente artigo é duplo: em primeiro lugar, problematizar a Entstehungsgeschichte ou história do surgimento da filosofia crítica a partir de um expediente interpretativo bem definido, a saber, a identificação de certos motivos críticos que auxiliam na determinação de continuidades e rupturas no desenrolar do pensamento de Kant. Em segundo lugar, analisar a primeira obra de Kant, os Pensamentos sobre a verdadeira estimação das forças vivas, buscando aplicar a ela o expediente interpretativo

* DKT: Doutor em Filosofia, e-mail: diegokosbiau@hotmail.com 
discutido anteriormente e, assim, reconhecer alguns motivos críticos que definem importantes linhas de continuidade na filosofia de Kant.

Palavras-chave: Kant. Entstehungsgeschichte. Pré-crítico. Motivos críticos.

\section{Abstract}

The aim of this paper is twofold: first, to discuss the Entstehungsgeschichte or the history of the formation of Kant's critical philosophy by means of a well-defined interpretive device, namely the identification of certain critical motives that help to determine continuities and ruptures in the development of Kant's thought. Second, to discuss Kant's first writing, Thoughts on the True Estimation of Living Forces, applying to it the interpretive device previously discussed and thereby recognizing some critical motives which determine important lines of continuity in Kant's philosophy.

Keywords: Kant. Entstehungsgeschichte. Precritical. critical motives.

\section{Introdução ${ }^{1}$}

Os Pensamentos sobre a Verdadeira Estimação das Forças Vivas², publicados em 1747, quando Kant ainda era um jovem estudante de 22 anos, não costumam despertar grande interesse na Kant-Forschung internacional e tampouco nas pesquisas sobre Kant em língua portuguesa. Segundo muitos intérpretes, tratar-se-ia de uma obra de um espírito ainda inexperiente e tateante; além disso, talvez de forma mais relevante para a desconsideração de que é objeto entre os estudiosos de Kant, a obra seria pertencente àquela fase em que Kant, de acordo com

\footnotetext{
10 presente artigo contou com o apoio da FAPESP e do DAAD.

2 Título completo é Pensamentos sobre a verdadeira estimação das forças vivas e julgamento das provas das quais Leibniz e outros mecanicistas se utilizaram nessa causa controversa, ao lado de algumas considerações prévias que dizem respeito à força dos corpos em geral (Gedanken von der wahren Schätzung der lebendigen Kräfte und Beurtheilung der Beweise, deren sich Herr von Leibniz und andere Mechaniker in dieser Streitsache bedient haben, nebst einigen vorhergehenden Betrachtungen, welche die Kraft der Körper überhaupt betreffen).
} 
a historiografia inicial da moderna Kant-Forschung, grosso modo de K. Fischer até B. Erdmann, estaria mais próximo do "dogmatismo" e, assim, ainda muito longe do "criticismo" de sua fase madura. Mesmo admitindo que nesta obra Kant ainda esteja indiscutivelmente distante do desenvolvimento conceitual acabado de muitos temas do período Crítico, o intuito do presente artigo é contestar a classificação das Forças Vivas como uma obra pura e simplesmente "dogmática". Pretende-se mostrar como verdadeiros motivos críticos são nela encontrados, como, por exemplo, o exame imparcial dos conflitos filosóficos e a necessidade de conciliá-los através de uma "proposição intermediária" na qual é solucionado o erro em que incorrem os partidos filosóficos em conflito. De acordo com essa possível releitura da história de surgimento da filosofia crítica, as Forças Vivas e demais obras das décadas de 1740 e 1750, ao invés de pertencerem a um "período dogmático" do percurso filosófico de Kant, fariam parte daquele recorte cronológico que N. Hinske denomina $1^{a}$ etapa da problemática da antinomia, a saber, a etapa irênica, contendo, pois, motivos críticos ainda em germe ${ }^{3}$. Contudo, ao invés de identificar os traços característicos do criticismo à temática mais ampla da antinomia da razão pura, como faz Hinske e outros, preferimos adotar uma abordagem interpretativa mais ampla e relacionar tais traços à ideia da Crítica como o tribunal crítico da razão, que busca resolver os conflitos da metafísica a partir de uma instância imparcial de decisão que dê razão às partes em conflito. Dessa maneira, como ficará claro adiante, preferimos aproximar os motivos críticos por nós identificados àquela "tendência conciliatória" profunda da filosofia kantiana de que fala Vaihinger (VAIHINGER 1881) e cuja amplitude conceitual extrapola a problemática da antinomia da razão pura.

3 N. Hinske argumenta haver três etapas, ou ainda, modelos da problemática da antinomia, a saber, a) o modelo irênico de solução (irenische Lösungsmodell) de 1747 a 1770, pelo qual a antinomia é tratada como "questões conflituosas concretas, de conteúdo"; b) o modelo de solução por separação (separierende Lösungsmodell) em 1770, mais especificamente 0 "dissenso entre a faculdade sensível e a intelectual" (MSI AA 02: 389) e a "aguda e fundamental separação entre mundo dos sentidos e mundo do entendimento" (HINSKE 1998: 122); c) e finalmente o modelo crítico de solução após 1770, quando a problemática das antinomias surge em toda sua força, isto é, "para designar a estrutura contraditória, justamente antinômica da razão". Cf. HINSKE 1970. 
Num primeiro momento, será discutido o problema de uma história de surgimento ou Entstehungsgeschichte da filosofia Crítica na bibliografia secundária, procurando questionar a divisão estanque de períodos de desenvolvimento e propondo, em lugar disso, a existência de motivos críticos que surgem ao longo do desenrolar do pensamento kantiano antes mesmo que eles se consolidem no período Crítico (1). Na sequência, examinaremos os principais temas de conteúdo e metodológico das Forças Vivas, buscando identificar e desenvolver os motivos críticos já presentes na obra que sinalizam uma linha de continuidade do pensamento pré-crítico ao crítico, tornando, assim, mais complexa a narrativa acerca do desenvolvimento filosófico de Kant (2).

\section{Problema de uma Entstehungsgeschichte da filosofia Crítica}

Toda história de surgimento ou formação da filosofia kantiana padece de uma arbitrariedade de origem. Narrar o surgimento e consolidação da Crítica da Razão Pura (KrV) à luz de um tema (antinomia ${ }^{4}$, problema do espaço ${ }^{5}$, dedução ou síntese transcendental ${ }^{6}$, causalida$\mathrm{de}^{7}$ ) ou mesmo da influência precisa de um autor (Hume ${ }^{8}$, Rousseau ${ }^{9}$ ou os "escoceses" ${ }^{10}$ ) coloca à sombra, forçosamente, toda a gama de temas e autores colaterais que, de uma forma ou de outra, influíram em partes doutrinais precisas da filosofia Crítica. Isso para não mencionar, decerto, a dificuldade de datação do material póstumo, o desafio em conciliar datas, explicar reviravoltas radicais e afastar elementos que atrapalham o esquema interpretativo adotado. Eleger algum "Grundantrieb" de Kant tampouco auxilia no alijamento da arbitrariedade. Contudo, de certa forma, ao isolar seu objeto e por princípio

\footnotetext{
4 Como veremos abaixo, sobretudo ERDMANN 1992, mas também HINSKE 1970, 1998 e muitos outros comentadores.

5 Destaca-se aqui FISCHER 1869.

6 P. ex. VLEESCHAUWER 1932.

7 P. ex. PAULSEN 1875.

8 P. ex. Idem.

9 P. ex. VELKLEY 1989.

10 P. ex. KUEHN, 1987.
} 
colocar sob parênteses outras visadas concorrentes, todo trabalho interpretativo padece, a rigor, da pecha de arbitrariedade e unilateralidade. A questão é como lidar com tal arbitrariedade e como definir seus limites e extensão.

K. Fischer foi quem colocou a pedra fundamental para a análise genética da obra kantiana que mobilizou o movimento neokantiano e que foi recentemente revivida ${ }^{11}$. Em sua Clavis Kantiana (1858), Fischer vê na Entstehungsgeschichte do pensamento de Kant a chave para a compreensão de sua filosofia, interpretando os escritos pré-críticos como uma aproximação contínua da filosofia crítica (FISCHER 2010: 217). Para ele, que vê no problema do espaço e da matemática o fio condutor do desenvolvimento filosófico de Kant, haveria um estrito espelhamento do aspecto genético no aspecto sistemático, a saber, a Entstehungsgeschichte da $\mathrm{KrV}$ teria percorrido suas etapas na mesma ordem das partes da $K r V:$ 1) Estética; 2) Analítica e 3) Dialética ${ }^{12}$. Ao propósito interpretativo genético de Fischer se ligaram, dentre muitos outros, explicitamente Paulsen (1875), Riehl (1876) e Erdmann (1878; 1992). Este, no entanto, lançando mão de material póstumo - até então não publicado - reverteu o princípio de espelhamento de Fischer e sugeriu que, na verdade, os temas da Dialética é que teriam recebido precedência no desenvolvimento do pensamento kantiano, mais especificamente a antinomia: a "descoberta" da antinomia teria levado à teoria da idealidade de espaço e tempo e, na sequência, à dedução transcendental ${ }^{13}$. Erdmann teria, assim, "provado de uma vez por todas" (VAIHINGER 1881: 436) ou "mostrado de forma bem conclusiva"

11 Para uma Entwicklungsgeschichte das "entwicklungsgeschichtlichen Interpretationen" da filosofia Crítica, Cf. CAMP0 1951: xxii e segs. E mais recentemente KREIMENDAHL 1990.

12 "Na Estética Transcendental, portanto, a filosofia crítica ou kantiana é estabelecida <posita>". (FISCHER 2010: 217). "A doutrina transcendental do tempo e do tempo é a descoberta de Kant que marcou época, o genuíno fundamento e pedra de toque da filosofia crítica". (FISCHER 1860: vi-vii). Fischer vê, no entanto, uma distinção anterior à própria teoria idealista de espaço e tempo, a saber, a distinção entre entendimento e sensibilidade: "Entendimento e sensibilidade <mens et sensus> são fundamentalmente duas faculdades distintas do conhecer". (FISCHER 2010: 219); esta distinção teria ocorrido no Über die falsche Spitzfindigkeit (Idem: 225-227).

13 Ao ressaltar o papel das antinomias no "despertar" de Kant, Erdmann toma posição explicita contra Paulsen e Vaihinger, que atribuem respectivamente a Hume e Leibniz (dos Nouveaux Essays) o impulso do despertar de Kant. (ERDMANN 1992: S. xxiii-xxiv). 
(KEMP SMITH 1993: 431-432) que a antinomia da razão pura foi o verdadeiro motivo desencadeador da filosofia transcendental no desenvolvimento intelectual de Kant (ERDMANN 1992: xxiv). Significativa parte da Kant-Forschung assumiu sua tese como uma communis opinio (KREIMENDAHL 1990: 69) e procurou seguir Erdmann nessa "intuição histórica certamente válida" ${ }^{14}$, buscando, com auxílio dos escritos pré-Críticos e do material póstumo, as causas da descoberta das antinomias e o momento preciso em que ela se $\mathrm{deu}^{15}$. Para tais intérpretes, o que haveria de "crítico" na filosofia Crítica seria em grande medida dependente do quão próximo ou distante determinada obra ou declaração de Kant estaria em relação à formulação "definitiva" da antinomia na $K r V$.

Não há dúvida, porém, que para muitos dos autores envolvidos na controvérsia a complexidade do tema impõe obstáculos a juízos mais simplistas e inflexíveis sobre datas, momentos e contextos precisos. Segundo eles, para além de questões filológicas envolvidas na datação das reflexões por Adickes, não é tarefa simples determinar se houve de fato algo como um único "despertar" no pensamento de Kant a ser atribuído à descoberta da antinomia da razão pura, e mesmo se esta e, de modo geral, a filosofia crítica se deixam interpretar como surgidas em um momento determinado, quase que ex nihilo. Mesmo que se admita a importância genética crucial da antinomia, não há consenso quanto a ela ter sido a peça doutrinal da Crítica que propulsionou o idealismo transcendental, sendo, assim, anterior às demais partes da Dialética e mesmo à Estética (cf. por exemplo SCHMUCKER, 1976).

Contra isso, muitos intérpretes, sobretudo mais contemporâneos, argumentam que faz mais sentido pensar no despontar da filosofia crítica como um longo processo, sujeito a pequenas porém numerosas

14 "Deve ser considerado atualmente como um discernimento histórico certo que [...] a temática das antinomias também teve um significado determinante, até mesmo decisivo para a gênese da filosofia de Kant". (HEIMSOETH 1960: 263).

15 Erdmann estabelece como que o princípio metodológico das investigações posteriores: para ele, "0 genuíno impulso" para as investigações metodológicas de Kant foram as antinomias, "cujos primeiros rudimentos podemos remeter até a primeira fase do dogmatismo [de Kant]". (ERDMANN 1992: xxxix). 
reviravoltas e influências ${ }^{16}$, do que um brusco e repentino "despertar", seja por Hume, seja pelas antinomias, seja (segundo uma ânsia de "harmonização" dos relatos autobiográficos de Kant) por ambos ${ }^{17}$. Nesse sentido, argumenta-se que a repartição do desenvolvimento da filosofia de Kant em momentos estanques - como o modelo padrão da historiografia kantiana de um início dogmático, seguido por um empirista, recaída cética e, então, o período racionalista e crítico, precedido por um inexplicável intermezzo dogmático na Dissertatio ${ }^{18}$ - é insustentável por ser, justamente, estanque e não fazer justiça ao dinamismo e à aporética do pensamento kantiano. Nessa nova leitura do desenvolvimento filosófico de Kant, motivos críticos se misturam a motivos "pré-críticos", elementos "progressivos e retardantes" (progressive e retardierende $)^{19}$ se apresentam em todos os escritos do período anterior à $\mathrm{KrV}$. Com efeito, como já escreveu D. Henrich, Kant é um "pensador muito dinâmico" (HENRICH, 1965). O problema para o historiador da filosofia kantiana "é frequentemente esta imensa dinâmica, que não raro torna difícil a compreensão de motivos e impulsos iniciais em virtude de múltiplas metamorfoses de pensamento quanto àquilo que Kant, por fim, enunciou" (KREIMENDAHL 1990: 76).

$\mathrm{O}$ que nenhum intérprete pode negar neste dinamismo conceitual de Kant é a persistência de certos motivos críticos ao longo do desenvolvimento de seu pensamento até a formulação da filosofia Crítica na $K r V^{20}$. Que estes motivos críticos percorrem várias "etapas" e são influenciadas por vários elementos, como Hume e a antinomia da razão pura, tampouco é algo que se pode seriamente colocar em dúvida. Ao invés, pois, do resultado de uma "descoberta" repentina, a filosofia

${ }^{16}$ Cf. sobre isso, HINSKE 1970: 12. “Um dos traços característicos do pensamento de Kant é 0 abandono de posições há muito fixadas, a atenuação de polêmicas acaloradas, a 'revisão' de programas revolucionários e a retomada de determinadas tradições; em uma palavra: a autocorreção tardia ou retrospectiva de 'projetos' antigos".

17 Para uma tentativa de conciliar o despertar por Hume com o despertar pela antinomia, Cf. KREIMENDAHL 1990. ERTL 1990. De resto, o livro de Kreimendahl oferece uma exposição completa do status quaestionis sobre a história do surgimento da filosofia crítica e dos elementos que teriam aí desempenhado um papel central.

18 Como se sabe, esta é grosso modo a repartição de Erdmann. Cf. ERDMANN 1992.

19 Estes são os termos utilizados por Kreimendahl para designar o que entendemos por motivos críticos e pré-críticos.

20 Quem fala explicitamente de "motivos críticos" na Entwicklungsgeschichte da filosofia Crítica é Adickes e Lehmann. Cf. ADICKES 1897; 1887. LEHMANN 1957. 
Crítica é melhor conceitualizada como o desdobramento de certos motivos críticos que percorrem várias etapas sucessivas, ou seja, como um surgimento gradual e não uma virada abrupta (cf. BRANDT 2007: 251. HINSKE 1970. ZAMMITO 2002: 259-260). Neste sentido, a análise do lento desenrolar de certos motivos críticos, desde o primeiro escrito de Kant até a sua forma "final" e crítica na $\mathrm{KrV}$, revela-se ao intérprete como um possível fio condutor do desenvolvimento do próprio pensamento de Kant ${ }^{21}$. Na sequência, procuraremos identificar o surgimento de alguns motivos críticos nas Forças Vivas relacionados a outras problemáticas mais amplas (como a da antinomia da razão pura), porém subsistentes por si mesmos. Reconhecer a presença de tais motivos logo na primeira obra de Kant implica negar que essa obra e as demais do período possam ser classificadas pura e simplesmente como "dogmáticas"; ademais, como produto colateral espera-se que essa e demais obras do primeiro período de Kant ganhem um renovado interesse nos estudos kantianos brasileiros.

\section{Os Pensamentos sobre a verdadeira estimação das forças vivas}

No prefácio às Forças Vivas Kant, prenuncia de forma explícita e autoconsciente a postura que adotaria em toda a sua obra filosófica: “Na sequência desse tratado não hesitarei em rejeitar de modo franco as proposições de homens tão célebres caso elas se apresentem ao meu entendimento como falsas" (GSK AA 01: 09).

Talvez mais do que o arroubo intempestivo de um espírito ainda inexperiente e cheio de si, esse pequeno trecho do prefácio à obra constitui uma significativa carta de intenções de um ambicioso estudante e dá claro sinais da ode à liberdade de pensamento e da recusa a todo e qualquer dogmatismo ou partidarismo em filosofia que conduziriam

${ }^{21}$ Hinske realiza isso relativamente às antinomias: "Na doutrina das antinomias - nesse meio tempo essa concepção consolidou-se amplamente na Kant-Forschung - trata-se não de uma problemática que surgiu no pensamento de Kant antes ou depois de 1770 como que caída do céu. Pelo contrário, alguns dos fios de que se compõe o novelo do problema prolongam-se até os primórdios do pensamento de Kant". (HINSKE 1998: 118). 
Kant à $K r V^{22}$. A imagem do tribunal presidido por um juiz imparcial, exposta à exaustão na $K r V$, é pressagiada nessa e noutras passagens da primeira obra de Kant, uma investigação de tom conciliatório sobre os conceitos opostos de força defendidos pelos "célebres" Leibniz e Descartes, e em cujo título, não por acaso, figura o termo jurídico Streitsache ou causa controversa. Com efeito, muitos comentadores notaram que nesta primeira obra de Kant já se encontram elementos significativos da futura filosofia Crítica. Esta conclusão, contudo, é relativamente recente. Para Erdmann, por exemplo, as Forças Vivas são na verdade um escrito "dogmático" ${ }^{23}$. Erdmann rejeita ver nas "afirmações de circunstância" da obra pensamentos que prenunciam o futuro criticismo: "elas não são nem tanto a expressão de discernimentos refletidos como, na verdade, arroubos juvenis de uma força intelectual extraordinária" ${ }^{24}$. Foram Cassirer, Vaihinger e B. Bauch aqueles que inicialmente questionaram esse juízo de Erdmann e ressaltaram o prenúncio claro de motivos críticos neste primeiro e supostamente "dogmático" escrito de Kant, como, por exemplo, a procura por uma proposição intermediária (Mittelsatz) que "dê razão às partes" (GSK AA 01: 32) (CASSIRER 1921: 28-29. VAIHINGER 1881: 58. BAUCH 1916: 25-26). Mais recentemente, já no interior do movimento que rompe com a classificação estanque dos períodos do desenvolvimento da filosofia kantiana e procura motivos críticos in nuce em todos os escritos pré-críticos, comentadores como N. Hinske (1970: 42; 83-84; 96-97; 108-109; 119-123), R. Brandt (2006: 150-1), F. Kaulbach (1982: 19-26), G. Tonelli (1959: 1-42) e

22 Adickes escreve que determinadas afirmações do prefácio "testemunham que certas tendências intelectuais que dominam 0 desenvolvimento futuro de Kant já são fortes no jovem de 22 anos: 0 ímpeto de verdade, 0 caminho para a independência em relação à coerção da escola". (ADICKES 1924: 67).

23 "A caracterização do primeiro período do desenvolvimento [do pensamento de Kant] como dogmatismo [...] corresponde a uma concepção geralmente aceita [...]. A localização de seu ponto de partida na época em torno de 1746, época da redação do primeiro escrito de Kant, não encontrará sérias reservas". (ERDMANN 1992: xiii-xiv). Em Martin Knutzen und seine Zeit Erdmann escreve que em seu primeiro escrito "Kant surge como um decidido partidário daquela corrente independente do wolffianismo à qual Knutzen pertencia como um de seus defensores mais importantes". (ERDMANN 1876: 143).

24 ERDMANN 1992: xv. Porém, Erdmann é um pouco ambíguo. Algumas páginas mais adiante ele escreve que "0 genuíno impulso" para as investigações metodológicas de Kant foram as antinomias, "cujos primeiros rudimentos podemos remeter até a primeira fase do dogmatismo [de Kant]". (IDEM xxxix). 
tantos outros ${ }^{25}$ procuraram mostrar como não apenas um ou outro, mas vários motivos críticos se anunciam nesse primeiro escrito de Kant. É neste mesmo espírito que analisamos aqui a obra.

O escrito sobre as Forças Vivas parte de uma controvérsia científica que opunha cartesianos e leibnizianos, a saber, se a força deve ser avaliada segundo a fórmula cartesiana do produto da massa pela velocidade $(m v)$ ou a fórmula leibniziana do produto da massa pelo quadrado da velocidade $\left(m v^{2}\right)^{26}$. Trata-se, grosso modo, do conflito entre uma concepção mecânica ou científica de movimento e outra dinâmica ou metafísica (GSK AA 01: 19-20). Com o objetivo de conciliar essas concepções distintas, Kant divide o escrito em três partes: na primeira são estabelecidos alguns conceitos metafísicos sobre a força dos corpos em geral (GSK AA 01: 17-31); a segunda é um longo exame das concepções dos leibnizianos sobre as forças vivas (GSK AA 01: 32-138); na terceira, por fim, Kant expõe sua própria concepção sobre as forças da natureza (GSK AA 01: 139-181). Dessa forma, é possível distinguir nas considerações de Kant o aspecto filosófico ou metafísico (parte I) do aspecto mais estritamente científico (partes II e III) da questão; no interior da segunda parte, mais precisamente nos $\S \S 48-51$ (GSK AA 01: 58-60) e §§ 88-90 (GSK AA 01: 93-101), surge, porém, um terceiro aspecto: o metodológico (CAMPO: 1959: 17-8), no qual nos concentraremos, ainda que não em toda sua extensão.

A tese conciliatória geral do escrito consiste em afirmar que a estimação das forças vivas, isto é, das forças que se apresentam na natureza, é feita a partir do quadrado da velocidade - nesse sentido os leibnizianos têm razão. Contudo, estes erram ao expandir suas conclusões a toda e qualquer espécie de movimento e força e também ao apoiá-las na matemática, já que esta, por sua vez, dá razão aos cartesianos. A forma de resolver o conflito ou Streitsache em questão consiste em propor uma correção metodológica pela qual se atribuem aos partidos em conflito âmbitos particulares de validade de suas proposições, desvelando

25 PETROCCHI 2004. STENZLER 1994: 7-27. TONELLI 1959: 1-42. WEBER 1976: 94-105.

${ }_{26}$ Para uma investigação sobre o conteúdo científico mesmo da obra, e nem tanto 0 aspecto metodológico que aqui nos interessa, Cf. ADICKES 1924. ARANA 1982; CAMPO 1959: 5 ss. 
o erro oculto em que ambos baseiam suas provas e, assim, conciliando-os (Cf. SCHÖNFELD 2000: 56). Há, pois, um "Schema" metodológico na obra que pode ser remetido ao futuro método crítico ${ }^{27}$ e que se coaduna com o motivo do tribunal e da legislação da razão ${ }^{28}$.

Dentre os muitos motivos críticos da obra que desaguam no do tribunal crítico da razão destacam-se os seguintes: a) a desconfiança em relação à metafísica e a limitação do conhecimento humano por meio de uma "coerção" (Zwang) ou "disciplina", ligada, de resto, à insuficiência e má aplicação do método matemático; b) a necessidade de dissolver a "discórdia e desunião entre os filósofos de todas as nações" (GSK AA 01: 148), procurando uma conciliação por meio da reflexão sobre as fontes do conflito e do erro em que este se apoia; c) isso implica a busca de um ponto de vista "exterior" ao das partes, o que implica, por sua vez, uma luta prévia contra preconceitos de modo a atingir uma consideração imparcial do problema; d) por fim, há o interesse no problema metodológico para além de questões específicas de conteúdo. Deixando de lado as possíveis fontes de tal postura metodológica de fundo, todos esses pontos sinalizam para o motivo crítico do tribunal da razão como instância de resolução dos conflitos da metafísica. Vejamos cada um deles na sequência.

27 Petrocchi resume da seguinte forma o Schema de resolução de conflitos filosóficos exposto nas Forças Vivas: "ele remonta em parte à 'regra na investigação das verdades' do wolffiano Bülfinger e em parte ao método de indiferença (Methode der Gleichgültigkeit) de Locke". (PETROCCHI 2004: 155-6). Seguindo as indicações dadas por R. Brandt e A. Winter, Petrocchi analisa a influência que a recepção do escrito póstumo de Locke, Of the Conduct of the Understanding, cuja tradução para 0 alemão foi iniciada por M. Knutzen e terminada por um aluno e conhecido de Kant, G. D. Kypke, pode ter exercido neste primeiro escrito de Kant, no qual, como resultado dessa influência, já estariam presentes elementos que apenas se cristalizariam ao longo do desenvolvimento da filosofia kantiana: a admissão de um ponto imparcial de ajuizamento, a recusa de preconceitos, a necessidade de conciliar os esforços filosóficos e, assim, acabar com a "desunião" entre os filósofos, etc. "Neste escrito Locke fala ao menos doze vezes sobre argumentos e linhas de pensamento contrapostos entre si, em cujo exame é preciso ser o mais indiferente possível em relação aos dois lados e no qual se deve, ademais, assumir a posição dos diferentes partidos para não deixar que preconceitos e tomadas de partidos determinem o resultado". (WINTER 1984: 109. (f. também WINTER 1986: 27-66).

28 N. Hinske vê nas Forças Vivas um prenúncio do método cético. Assim como este, o "método" das Forças Vivas teria uma parte negativa: descobrir o "fundamento do erro", e outra positiva: encontrar uma "proposição intermediária" que concilie as partes em conflito. Como já dito, Hinske centra sua análise das Forças Vivas e dos demais escritos deste primeiro período do desenvolvimento da filosofia kantiana no horizonte da "problemática da antinomia" e da origem polêmico-teológica do conceito kantiano de antinomia. Cf. HINSKE 1972: 58. 
Assim como ocorre no prefácio B à $\mathrm{KrV}$ e em outros escritos pré-críticos, nas Forças Vivas Kant reconhece a falta de certeza e convicção pertencente à metafísica da época: "Como muitas outras ciências, nossa metafísica está, de fato, apenas no limiar de ser um conhecimento realmente rigoroso" (GSK AA 01: 30). A ausência de um tal conhecimento sólido radica no "preconceito" a que seus partidários estão sujeitos na tentativa de "ampliar" o conhecimento humano: "Encontra-se muito frequentemente o preconceito como a maior força da prova. Nada é mais culpado por isso do que a inclinação dominante daqueles que procuram ampliar o conhecimento humano" (GSK AA 01:31). Segundo Kant, o entendimento é "inclinado à aprovação" (Beifall); é difícil pedir-lhe que não confie em sua própria aprovação, se cale sobre as imperfeições de suas próprias descobertas e não seja tão vaidoso para preferir à verdadeira utilidade do conhecimento a satisfação (Vergnügen) da fantasia ou imaginação (Einbildung) de uma pretensa ciência rigorosa. Por esse motivo, cumpre exercer coerção (Zwang antun) no entendimento para que ele sacrifique tudo em nome de um "conhecimento bem fundado": "O entendimento é bem inclinado à aprovação e é manifestamente muito difícil contê-lo; contudo, deve-se ao final exercer essa coerção, para que se sacrifique a um conhecimento rigoroso tudo aquilo que, em si mesmo, tem um grande atrativo" (GSK AA 01: 31). Percebem-se nestas e outras passagens motivos críticos como o da falta de "cientificidade" da metafísica, o da necessidade de uma "coerção", isto é, uma "disciplina", e o da incerteza repousar em um "preconceito" que macula a tentativa de ampliar o conhecimento humano.

Para resolver o conflito entre leibnizianos e cartesianos, cumpre encontrar uma nova lei de medição das forças que unifique as "cabeças filosóficas". A nova lei proposta por Kant é a seguinte: "um corpo que, num movimento livre, conserva sua velocidade constante até o infinito, tem uma força viva, isto é, uma força tal que é medida pelo quadrado da velocidade" (GSK AA 01: 148). Essa lei é o "fundamento da verdadeira dinâmica" e pode ser a responsável pelo término da "discórdia e desunião entre os filósofos de todas as nações". Ora, a causa da confusão anteriormente existente é, segundo Kant, a aplicação da matemática à 
ciência da natureza (entendida aqui, porém, como uma disciplina da metafísica); sua "nova lei" poderia remover esse erro de base:

Essa lei é o fundamento primeiro da nova estimação das forças; eu colocaria tal lei no lugar das estimativas de Descartes e Leibniz caso a insignificância de meus juízos em comparação a homens tão grandes, dos quais aqui trato, me permitisse falar com tal autoridade. Todavia, não deixo de estar convencido de que tal lei possa, talvez, determinar aquele objetivo cujo lapso provocou a discórdia e desunião entre os filósofos de todas as nações. As forças vivas são acolhidas na natureza após serem expulsas da matemática. Não se deve em absoluto imputar o erro a nenhum dos dois grandes filósofos, nem a Leibniz nem a Descartes. Até mesmo na natureza a lei de Leibniz não seria encontrada em nenhum lugar se antes não fosse medida segundo a estimativa de Descartes (GSK AA 01: 148-149).

Com a formulação de uma nova lei que suprime o problema da aplicação da matemática à física, Kant procura encontrar o ponto de concórdia entre esses dois filósofos, isto é, obter um "ponto médio" em que os partidos se reencontram com a verdade comum a ambos, o que, por sua vez, significa defender a "honra da razão humana", na medida em que ela é "unificada" ou "reconciliada" consigo mesma, numa clara alusão à futura antitética da razão pura e a necessidade de reconciliá-la consigo mesma:

Trata-se, por assim dizer, de uma defesa da honra da razão humana quando ela é unificada consigo mesma (mit sich selber vereinigt) nas diferentes pessoas de homens tão perspicazes e é encontrada a verdade [...] quando estes parecem contradizer-se (GSK AA 01: 149).

Assim como ocorre na antitética da razão pura da $K r V$, Kant liga à "unificação" da razão consigo mesma e à defesa de sua "honra" a descoberta da "fonte do erro", para a qual devem valer os preceitos metodológicos de imparcialidade, multilateralidade e moderação. Kant ilustra o método por ele empregado voltando-se inicialmente à forma como os partidos em conflito procuram fundamentar suas asserções. O conflito radical na concepção de força assumida por cada partido 
baseia-se, de partida, num conceito de movimento não compartilhado pelo partido oposto. Ambos se recusam a encerrar suas concepções em limites determinados, o que faria com que as teses do partido oposto fossem válidas sob certas circunstâncias; inversamente, ambos negam de maneira absoluta os argumentos do adversário. Kant dá o exemplo da lei de Leibniz:

Antes de Leibniz, o mundo cultuou aquela proposição de Descartes que, para a medida de sua força, atribuía aos corpos, mesmo àqueles que se encontram num movimento atual, apenas a mera velocidade. A ninguém ocorreu ser possível encontrar nela alguma dúvida; apenas Leibniz colocou de pronto a razão humana em alvoroço por meio da enunciação de uma nova lei que, com o tempo, tornou-se uma das leis que provocou as maiores disputas entre os eruditos. Descartes havia pura e simplesmente estimado as forças dos corpos moventes segundo as velocidades, apenas Leibniz colocou como medida o quadrado de sua velocidade. Ao contrário do que se deve pensar, ele não expôs essas leis apenas sob certas condições que concediam às anteriores algum espaço; não, ele negou a lei de Descartes de forma absoluta e sem restrições, colocando em seu lugar a sua própria (GSK AA 01: 33).

A postura "despótica" de Leibniz é denunciada por Kant. Não se deve negar pura e simplesmente a posição cartesiana, mas, antes, é preciso conceder-lhe "certa razão" e designar-lhe um âmbito preciso de validade. Ora, sabemos que essa solução é análoga àquela que Kant propõe na antinomia da razão pura: tese e antítese podem ser ou ambas falsas, como no caso dos dois primeiros conflitos cosmológicos, ou ambas verdadeiras, como no caso dos dois últimos conflitos cosmológicos da razão pura. Em cada caso, as posições em conflito têm âmbitos de validade excludentes ou compatíveis entre si.

Os temas metafísicos específicos tratados na futura antinomia da razão pura (divisibilidade infinita do espaço, liberdade e determinismo, etc.) não estão, decerto, presentes aqui; contudo, a postura metodológica para resolução do conflito é fundamentalmente a mesma. Ora, a despeito das divergências, a convicção dos partidos deve ser comum; ambos se puseram em conflito acusando os preconceitos do adversário e acreditando que seus próprios argumentos estariam livres de dúvida 
se o oponente os colocasse no "reto equilíbrio" 29 das "inclinações do ânimo". Cada parte procurou fundamentar seus argumentos de maneiras distintas: os cartesianos a partir de "casos simples", nos quais "a decisão sobre a verdade e o erro é fácil e certa", já os leibnizianos por meio de demonstrações "complicadas e obscuras", procurando, pela impressão de profundidade, vencer a contenda.

Relativamente à própria opinião, tanto o partido de Descartes como o de Leibniz encheram-se de toda convicção de que é comumente capaz o conhecimento humano. De ambos os lados, a queixa foi somente em relação ao preconceito do adversário, e cada partido acreditou que seria impossível que sua opinião fosse colocada em dúvida caso o oponente apenas se esforçasse seriamente em considerá-la num reto equilíbrio das inclinações do ânimo. Entretanto, mostra-se uma certa diferença digna de nota entre o modo com que o partido das forças vivas busca sustentar-se e o daquele que defende a estimação de Descartes. Este refere-se apenas a casos simples, nos quais a decisão da verdade e do erro é fácil e certa; aquele, pelo contrário, torna suas provas tão complicadas e obscuras quanto possível, e se salva, por assim dizer, com ajuda de um combate realizado à noite, no qual, fosse ele realizado com a devida luz da claridade, talvez eles levassem a pior (GSK AA 01: 15).

O tom exacerbado e agressivo da controvérsia impede que se analisem com calma e imparcialidade as teses e argumentos do adversário, retirando do leitor o prazer de entregar-se, ele mesmo, ao exame das razões em conflito; ora, segundo Kant, quem acusa e ridiculariza o adversário pretende encontrar na sua própria tese um "estado de repouso" (Ruhestand) e aí permanecer, afastado de toda "meditação penosa". Uma exposição "séria" do debate atrai o leitor e deixa a "alma" aberta a "todas as razões que podem, de um lado ou de outro, penetrar-lhe". Discutindo os argumentos de uma partidária do leibnizianismo, a Marquesa de Châtelet, contra os de um partidário do cartesianismo, Jean-Jacques d'Ortous de Mairan, Kant escreve:

29 Sobre a tese do "reto equilíbrio" e a influência que o escrito póstumo de Locke exerceu sobre Kant, Cf. PETROCCHI, I. 2004. 
Não posso aqui evitar de fazer uma observação sobre o modo como a Sra. Châtelet ataca os teoremas de seu adversário. Creio que ela não teria elegido método melhor para desferir nele o golpe mais sensível, na medida em que se ocupou em dar às suas conclusões o ar de algo estranho e extravagante. Uma apresentação séria atrai o leitor à atenção e investigação apropriadas, deixando sua alma aberta a todas as razões que podem, de um lado ou de outro, penetrar-lhe. Contudo, a curiosa figura na qual ela faz surgirem as opiniões do adversário apodera-se ao mesmo tempo do lado fraco do leitor e aniquila nele a vontade de toda ponderação adicional. A força da alma que rege a avaliação e a reflexão é de uma natureza calma e indolente; ela se satisfaz em encontrar o ponto de repouso e de bom grado permanece serenamente nele, o que a exime de uma reflexão mais cansativa; por conseguinte, ela se deixa vencer por aquelas apresentações que de pronto rebaixam uma das duas opiniões à mera verossimilhança e definem como desnecessário o esforço de investigações ulteriores. Nossa filósofa, portanto, teria podido empregar com mais justiça ou melhor sucesso seu ridendo dicere verum, ou seja, a sugestão de dizer rindo a verdade a seu adversário, caso este tivesse sido incapaz de razões mais sérias, e se tivesse desejado fazê-lo sentir seu ridículo (GSK AA 01: 132-133).

Ora, o modo "sério" de conduzir as provas é aquele que faz o leitor "refletir" e investigar por si as razões avançadas. Kant é claro a respeito do modo de obtenção da lei que expressa a "verdade" comum à qual os partidos se referem sem sabê-lo: cumpre seguir o caminho daquele que futuramente, na $\mathrm{KrV}$, seria denominado método cético, a saber, ouvir as razões contrárias, procurar examinar os argumentos opostos com indiferença e imparcialidade - ou seja, entrar num estado de "equilíbrio do entendimento" (Gleichgewichte des Verstandes), unicamente no qual a verdade pode ser atingida, evitando, assim, os erros na filosofia.

O ideal de "equilíbrio" do entendimento é elucidado por Kant com auxílio de uma crítica ao modo como os leibnizianos evitam investigar as forças vivas a partir do choque dos corpos inelásticos pelo simples fato de isso depor contra sua própria teoria: 
Um pequeno subterfúgio, uma fria e desbotada desculpa é capaz de satisfazê-los, quando se trata de afastar uma dificuldade que impõe obstáculos à opinião por eles adotada. Teria sido possível poupar muitos erros na filosofia se uma coerção tivesse sido exercida nesta parte. Se se está no caminho de aduzir todas as razões que o entendimento oferece para a confirmação de uma opinião assumida, então se deve esforçar com toda atenção e empenho para fundamentar o contrário através de todas as provas que forem possíveis, da mesma forma com que se procede em relação a uma opinião pela qual se tem apreço. Não se deve menosprezar o que parece ser minimamente favorável à opinião contrária, e deve-se empenhar-se ao máximo na defesa da mesma. Em um tal equilíbrio do entendimento seria frequentemente recusada uma opinião que, do contrário, teria sido assumida como infalível, e a verdade, caso ela finalmente surgisse, seria exposta numa luz de convicção tanto maior (GSK AA 01: 68).

Assumindo uma posição que se silencia sobre os próprios erros cometidos e na qual os argumentos contrários são tratados com leviandade, cada partido tornou difícil a obtenção de um ponto comum onde repousa a verdade em toda sua força de convencimento. Ao final do escrito, após julgar ter resolvido o conflito entre cartesianos e leibnizianos, Kant menciona que bastou uma "ausência de partidarismos" para atingir tal ponto comum:

Após os esforços dos cartesianos não era difícil prevenir, com a matemática, a confusão da estimativa pelo quadrado, e após as engenhosas medidas dos leibnizianos era quase impossível não encontrá-la na natureza. O conhecimento desses dois limites extremos teria de, sem dificuldade, determinar o ponto em que o verdadeiro coincidia nos dois lados. Para encontrá-lo, não era necessário nada mais do que uma grande perspicácia, era preciso apenas uma pequena ausência de partidarismo e um leve equilíbrio das inclinações do ânimo; assim as queixas acabaram de imediato (GSK AA 01: 181).

Como ocorrerá com a representação do tribunal crítico enquanto uma instância imparcial de decisão, Kant defende que da "ausência de partidarismos" no exame da questão resulta a consideração de um 
"ponto intermediário" que "dê em parte razão aos dois partidos". Kant ilustra isso com uma referência ao método de Georg Bernhard Bilfinger:

No tratado que o Sr. Bilfinger submeteu à academia de S. Petersburgo eu encontro uma consideração de que sempre me servi como uma regra na investigação das verdades. Quando homens de bom entendimento, nos quais a suspeita de propósitos escusos não é encontrada nem de um lado nem de outro, afirmam opiniões que se contrariam entre si, então é conforme à lógica da verossimilhança dirigir a atenção preferencialmente a uma certa proposição intermediária que, em certa medida, dá razão a ambos os partidos (GSK AA 01: 32. Grifo meu) ${ }^{30}$.

No parágrafo seguinte Kant menciona o "caso controverso" (Streitsache) das forças vivas e afirma que ambos os partidos, "segundo parece, são igualmente fortes e igualmente corretos". Kant prometia assumir no escrito o "caminho mais seguro pelo qual faz-se justiça a ambos os partidos" (idem). Tal "método mais seguro" é o "método do caminho intermediário" (SCHÖNFELD 2000: 56-62). Como forma de alcançar a "ausência de partidarismos" e, assim, o "ponto intermediário", Kant enuncia um preceito metodológico que ressurgirá ao longo do período pré-crítico e também no período crítico: para atingir o ponto intermediário, é necessário, antes, questionar as capacidades do entendimento humano em obter respostas a todas as suas perguntas, ou seja, duvidar das próprias convicções, mesmo as mais arraigadas, deixando o entendimento em um "equilíbrio" suficiente até que ele possa analisar e examinar cuidadosamente as demonstrações e seus contrários:

30 Cf. HINSKE 1970: 124-126. 0 livro de Bülfinger a que Kant faz referência é De viribus corpori moto insitis et illarum mensura. Aqui 0 autor defende uma "exposição imparcial das posições contrapostas entre si (alterius partis argumenta audias)" onde é questionado se os argumentos são, em ambos os lados, plausíveis. Kant se opõe a Bülfinger ao rejeitar o seu modo de colocar os dois lados em acordo ("conceder, sob certa medida, direito a ambos os partidos" [der beiden Parteien in gewisser Maße Recht lässet]), a saber, por "distinções" ou "diferenciações" (Distinktionen oder Unterscheidungen). Essa rejeição se encontra também no período Crítico - B xxxii. Kant, em lugar disso, afirma que o conflito pode ser resolvido se se revela que ele parte de um pressuposto equivocado (cf. também B 556); nos Gedanken, essa pressuposição falsa é a de que as forças vivas são demonstráveis ou refutáveis por meios matemáticos. "Esse falso pressuposto é, na opinião de Kant, a verdadeira fonte da discórdia: portanto, sua descoberta significa a conciliação - ao menos em princípio - das controvérsias e a'reconciliação dos partidos adversários"' (HINSKE 1970: 126). 
Ele [scil. Bernouilli] fala: não entendo o que o mais teimoso dos adversários, fosse ele até mesmo um cético, poderia opor a tal demonstração inteiramente evidente, e na sequência: certamente não está em nosso poder forçar alguém a admitir que amanhece quando o sol surge no horizonte. Consideremos esse deslize da razão humana na pessoa de um homem tão grande não com indiferença, mas aprendamos daí a colocar uma sábia desconfiança mesmo na nossa maior convicção e a supor em todos os casos que tampouco nos encontramos fora do perigo de nos enganar, para com isso manter o entendimento em seu equilíbrio ao menos até ele ganhar tempo para, num exame satisfatório, conhecer com as circunstâncias, a prova e seu oposto (GSK AA 01: 134. Grifo meu).

Dessa forma, o "método do caminho intermediário" é o Fazit metodológico do escrito sobre as Forças Vivas. Kant exprime isso em uma passagem da obra: "Nós questionamos aqui não propriamente a coisa mesma, mas o modo de conhecimento (modum cognoscendi)" (GSK AA 01: 60). O escrito sobre as Forças Vivas pode ser considerado, portanto, como uma reflexão sobre os motivos e método de resolver o conflito entre o modus cognoscendi matemático e o modus cognoscendi metafísico no que diz respeito à questão sobre a natureza e modo de avaliação das forças vivas. Para a resolução desse conflito de modos de conhecimento é que fazem sentido os preceitos metodológicos avançados por Kant. O "novo" método que ele propõe permite encontrar erros lá onde a mais estrita demonstração geométrica não os reconhece - em uma palavra, Kant, adiantando mais um de seus motivos críticos centrais, se volta contra a imitação do mos geometricus em filosofia:

Em uma palavra, todo esse tratado deve ser pensado única e exclusivamente como o resultado desse método [scil: o método que Kant propõe, não o método geométrico]. Eu devo admitir sinceramente: no início eu considerei todas essas provas das forças vivas, cuja fraqueza eu agora creio apreender perfeitamente, como demonstrações geométricas nas quais não suspeitava do menor erro e talvez tampouco teria encontrado algum caso a ponderação geral das condições sob as quais a estimativa 
do Sr. Leibniz é realizada não tivesse dado a meu modo de ver um impulso completamente diferente (GSK AA 01: 94).

O "despertar por Leibniz" levou Kant a ver que as concepções matemáticas das forças vivas assumem um pressuposto equivocado, a saber, que "a força do corpo movido [...] deve ser estimada como a força do corpo posto em movimento" e, assim, que a lei da medição de todas as forças é a do quadrado de sua velocidade. Os geômetras utilizam então tal pressuposto equivocado como premissa menor e daí extraem conclusões equivocadas:

Discerni, então, com uma certeza que a geometria não permitia, que a realidade do movimento não pode ser um fundamento suficiente para inferir que as forças dos corpos nesse estado têm de ser o quadrado de sua velocidade, pois elas não têm nada além da velocidade como medida em um movimento cuja duração é infinitamente pequena ou, o que dá no mesmo, na mera propensão a ele. Disso conclui que, se a matemática só tem a realidade do movimento como fundamento da estimativa pelo quadrado e nenhuma outra, então suas conclusões têm de ser bem capengas (GSK AA 01: 94-95).

A ausência desse método é, pois, o motivo para a persistência do erro:

A falta desse método foi a causa de que certos erros manifestos tenham permanecido por tanto tempo encobertos. Se se tivesse podido sempre aplicar esse modo de pensar, então teriam sido poupados muitos erros na filosofia, ao menos teria havido um meio de livrar-se deles muito mais cedo. Eu me atrevo a dizer que a tirania dos erros sobre o entendimento humano, que por vezes durara séculos inteiros, provém da falta desse método ou de outro que lhe seja aparentado, e que ele deve ser aplicado de agora em diante para prevenir futuramente todo o mal. Nós desejamos provar isso (GSK AA 01: 95).

Kant se refere à descoberta do erro escondido em determinada inferência para, assim, invalidar as provas que nela se baseiam: ora, enquanto o erro não for descoberto, a prova irá enganar perpetuamente. 
Porém, o problema maior ocorre quando o tal erro repousa justamente lá onde menos se suspeita que ele possa residir, ou seja, quando a prova baseada no erro é conduzida com "rigor e exatidão geométricos" (geometrische Schärfe und Richtigkeit); pode ocorrer que ele "permaneça escondido por muito tempo antes de ser descoberto, pois esse afortunado acaso pode durar anos, até mesmo, não raro, séculos inteiros. Esta é, por assim dizer, a primeira origem dos erros que, para vergonha do entendimento humano, permanecem por muito tempo" (GSK AA 01: 95-96).

À parte claras diferenças, o diagnóstico de Kant sobre a fonte do erro e os contornos do método para sua supressão permanece o mesmo até a $K r V$. Não é exagerado dizer, portanto, que um prenúncio do método "conciliador" do tribunal da razão como motivo crítico se encontra já nas linhas do primeiro escrito kantiano. Nesse sentido, as Forças Vivas são também uma obra de caráter metodológico, ainda que não tão diretamente como, por exemplo, o Preisschrift. Nelas já está presente o "espírito conciliatório" de Kant, seu esforço em investigar a causa da discórdia dos esforços filosóficos, na medida em que ela é interpretada como repousando num "erro", num "pressuposto equivocado" assumido por ambas as partes e que provoca o desacordo. É certo que para um exame mais completo e aprofundado sobre os motivos críticos presentes já nas Forças Vivas e demais obras pré-críticas seria necessário dedicar um espaço bem maior do que aquele possível no presente artigo; no entanto, esperamos que o que aqui foi apresentado, ao lado, naturalmente, de toda a bibliografia secundária produzida nas últimas décadas, baste para que o juízo sobre o suposto caráter inequivocamente dogmático do escrito sobre as forças vivas - e a fortiori do período pré-Crítico - seja devidamente sepultado na Kant-Forschung, bem como o interesse pela obra seja despertado nos estudos kantianos de língua portuguesa. 


\section{Referências}

ADICKES, E. “Die Bewegenden Kräfte in Kants philosophischer Entwicklung und die beiden Polen seines System". In: Kant-Studien, 1, 1897.

ADICKES, E. Kants Systematik als Systembildener Factor. Berlin: Mayer \& Müller, 1887.

ADICKES, E. "Einleitung". In: Immanuel Kants Kritik der reinen Vernunft mit einer Einleitung und Anmerkung. Berlin, 1889.

ADICKES, E. Kant als Naturforscher. Bd. I-II. Berlin: de Gruyter, 1924-5.

ARANA, J. Ciencia y Metafisica en el Kant Precritico. Sevilla: Universidad de Sevilla, Secretariado de Publicaciones, 1982.

BAUCH, B. Geschichte der Philosophie V. Immanuel Kant. Berlin \& Leipzig, 1916.

BRANDT, R. "Philosophical Methods". In: Haakonseen, K (Hrsg). The Cambridge History of Eighteenth-Century Philosophy. Bd 1. Cambridge: Cambridge University Press, 2006.

BRANDT, R. Die Bestimmung der Menschen bei Kant. Hamburg: Meiner, 2007.

CAMPO, M. La Genesi del Criticismo Kantiano. Varese: Ed. Magenta, 1959.

CASSIRER, E. Kants Leben und Lehre. Berlin: 1921.

ERDMANN, B. Martin Knutzen und seine Zeit: ein Beitrag zur Geschichte der Wolfischen Schule und insbesondere zur Entwicklungsgeschichte Kants. Leipzig, 1876.

ERDMANN, B. Kants Criticismus in der ersten und zweiten Auflage der $\mathrm{KrV}$. Leipzig, 1878.

ERDMANN, B. “Die Entwicklungsperioden von Kant theoretischer Philosophie". In: Reflexionen Kants zur kritischen Philosophie. aus Kants handschriftlichen Aufzeichnungen. Hrsg. von Benno Erdmann. Neudr. der Ausg. Leibzig 1882/1884. Neu hrsg, und mit einer Einl. vers. von Norbert Hinske. Stuttgart-Bad Cannstatt: Frommann-Holzboog, 1992. 
ERDMANN, B. "Einleitung zu der Kritik der reinen Vernunft" In: Kant, I Akademieausgabe Bd 4. 1911.

ERTL, W. David Hume und die Dissertation von 1770: eine Untersuchung zur Entwicklungsgeschichte der Philosophie Immanuel Kants. Frankfurt am Main [u.a.]: Lang, 1999.

FISCHER, K. Kants Leben und die Grundlagen seiner Lehre. Mannheim: Verlagsbuchhandlung Friedrich Bassermann, 1860.

FISCHER, K. Geschichte der neuern Philosophie. Bd III. Kant's Vernunftkritik und deren Entstehung. 2. rev. Aufl. Heidelberg: Verlagsbuchhandlung von Friedrich Bassermann. 1869.

FISCHER, K. “Clavis Kantiana”. Übers. und einl. von Schmid, A. In: BUSCHE, H. (Hrsg). Kant als Bezugspunkt philosophischen Denkens: Festschrift für Peter Baumanns zum 75. Geburtstag. Würzburg: Königshausen \& Neumann, 2010.

HEIMSOETH, H. Atom, Seele, Monade. Historische Ursprünge und Hintergründe von Kants Antinomie der Teilung. Mainz/Wiesbaden, 1960.

HENRICH, D. „Über Kants Entwicklungsgeschichte“. In: Philosophische Rundschau, 13. 1965.

HINSKE, N. "Kants Begriff der Antinomie und die Etappen seiner Ausarbeitung". In: Kant-Studien 56, 1965.

HINSKE, N. Kants Weg zur Transzendentalphilosophie. Stuttgart: Kohlhammer, 1970.

HINSKE, N. "Kants Begriff der Antithetik und seine Herkunft aus der protestantischen Kontroverstheologie des 17. und 18. Jahrhunderts. Über eine unbemerkt gebliebene Quelle der Kantischen Antinomienlehre". In: Archiv für Begriffsgeschichte, 16. 1972.

HINSKE, N. "Georg Friedrich Meier und das Grundvorurteil der Erfahrungserkenntnis. Noch eine unbemerkte Quelle der Kantschen Antinomienlehre. $\mathrm{Zu}$ den Grundimpulsen der Kritik der reinen Vernunft". In: Zwischen Aufklärung und Vernunftkritik. Studien zum Kantischen Logikcorpus. Stuttgart-Bad Cannstatt: Frommann-Holzboog, 1998. 
KAULBACH, F. Immanuel Kant. Berlin \& New York: Walter de Gruyter, 1982.

KANT, I. Gesammelte Schriften: herausgegeben von der Deutschen Akademie der Wissenschaften. 29 vols. Berlin: Walter de Gruyter, 1900-.

KANT, I. Pensamientos sobre la verdadera estimacion de las fuerzas vivas. Tradução, introdução e comentários por Arana, J. Bern [u.a.]: Peter Lang, 1988.

KEMP SMITH, N. A Commentary to Kant's Critique of Pure Reason. 2. ed., rev. and enl., reprinted - Atlantic Highlands, NJ : Humanities Press Internat., 1993. KREIMENDAHL, L. Kant - der Durchbruch von 1769. Köln : Dinter, 1990.

KUEHN, M. Scottish Common Sense in Germany. 1768-1800. A contribution to the history of critical philosophy. Kingston [u.a.] : McGill Queens Univ. Press, 1987.

LEHMANN, G. "Voraussetzungen und Grenzer systematischer Kantinterpretation”. In: Kant-Studien, 49, 1958.

LEHMANN, G. "Kritizismus und kritisches Motiv in der Entwicklung der kantischen Philosophie“. In: Kant-Studien, 1957. pp. 25-54.

PAULSEN, F. Versuch einer Entwicklungsgeschichte der Kantischen Erkenntnistheorie. Leipzig, 1875.

PETROCCHI, I. Lockes Nachlaßschrift Of the Conduct of the Understanding und Ihr Einfluß auf Kant. Frankfurt: Peter Lang, 2004.

RIEHL, A. Geschichte und Methode des philosophischen Kritizismus. Bd I-II. Leipzig, 1876.

SCHMUCKER, J. „Was entzündete in Kant das große Licht von 1769?“. In: Archiv für Geschichte der Philosophie, 58, 1976.

SCHÖNFELD, M. The Philosophy of the Young Kant: The Precritical Project. Oxford: Oxford University Press, 2000.

STENTLER, F. Die Verfassung der Vernunft. Berlin: publica, 1994.

TONELLI, G. Elementi metodologici e metafisici in Kant dal 1745 al 1768. Saggio di sociologia della conoscenza. Turin: Edizioni di 'Filosofia', 1959. 
VAIHINGER, H. Commentar zu Kants "Kritik der reinen Vernunft". Bd 1. Stuttgart: Verlag von W. Spemann. 1881.

VELKLEY, R Freedom and the End of Reason. On the moral foundations of Kant's critical philosophy. Chicago \& London: The University of Chicago Press, 1989.

VLEESCHAUWER, H. J. La Déduction Transcendentale dans l'Oeuvre de Kant. Tomes I-III. New York \& London: Garland Publishing, Inc, 1976. Reeimpressão de Antwerpen: De Sikkel, 1934.

WEBER, L. Das Distinktionsverfahren im mittelalterlichen Denken und Kants skeptische Methode. Meisenheim am Glan: Verlag Anton Hain. 1976.

WINTER, A. "Seele als Problem in der Transzendentalphilosophie Kants". In: KREMER, K. (Hrsg). Seele: Ihre Wirklichkeit, ihr Verhältnis zum Leib und zur menschlichen Person. Leiden \& Köln: E. J. Brill, 1984.

WINTER, A. „Selbstdenken - Antinomien - Schranken. Zum Einfluss des späten Locke auf die Philosophie Kants“. In: Aufklärung, 1, 1986. 27-66.

ZAMMITO, J. Kant, Herder, and the Birth of Anthropology. Chicago: Chicago University Press, 2002.

Recebido: 20/04/2016

Received: 04/20/2016

Aprovado: 03/06/2016

Approved: 06/03/2016 